\title{
Insurers' risk management as a business process: a prospective competitive advantage or not?
}

Insurers' RM as a business process

\author{
School of Foreign Language, Shanghai Jianqiao University, Shanghai, China; \\ Department of Business Administration, \\ HANDS - Institute of Development Studies (HANDS-IDS), Karachi, Pakistan and \\ Center for Islamic Finance, University of Bolton, Bolton, UK \\ Xie Yuantao \\ School of Insurance and Economics, \\ University of International Business and Economics, Beiing, China, and \\ Umair Saeed Bhutta \\ University of Technology and Applied Sciences, Ibri, Oman
}

Danish Ahmed

\begin{abstract}
Purpose - Insurance companies exist to manage the risk of others, which is why they are perceived to be competitive in risk management (RM). Considering this, we investigate how different RM capabilities make insurers effective in RM. These capabilities include understanding risk and risk management (URRM), risk identification (RI), risk assessment and analysis (RAA) and risk monitoring (RMON) activities in insurance companies. In addition, the authors probe how these capabilities can jointly yield a competitive advantage for the insurance industry under the resource-based view (RBV) and dynamic capabilities perspective (DCP).

Design/methodology/approach - The authors present a latent variable RM model for the insurance industry and employ structural equation modeling (SEM) to test the hypotheses. Furthermore, the authors also conduct confirmatory factor analysis ( $\mathrm{CFA}$ ) and convergent and discriminant validity analysis for model fit and invariance testing, respectively.

Findings - The results show that insurers who investigated RM-related capabilities directly influence their risk management practices (RMPs). Moreover, improving these capabilities will make insurers more effective in managing the risks of others. Thus, RM as a business process will yield a competitive advantage for the insurance sector. The findings are supported by the theoretical insights presented by the RBV and DCP. Furthermore, the model also adheres to the convergent and discriminant validity cut-off values.

Originality/value - To the best of the authors' knowledge, this is the first study examining insurers' RM practices as a source of a competitive advantage.

Keywords Risk management practices, Resource-based view, Dynamic capabilities perspective, Competitive advantage, Developed and emerging markets

Paper type Research paper

(C) Danish Ahmed, Xie Yuantao and Umair Saeed Bhutta. Published in European Journal of Management and Business Economics. Published by Emerald Publishing Limited. This article is published under the Creative Commons Attribution (CC BY 4.0) licence. Anyone may reproduce, distribute, translate and create derivative works of this article (for both commercial and non-commercial purposes), subject to full attribution to the original publication and authors. The full terms of this licence may be seen at http:// creativecommons.org/licences/by/4.0/legalcode

This paper forms part of a special section "Innovation, Management, and Governance for Sustainable Growth", guest edited by Alba Yela Aránega.
\end{abstract}

Received 1 August 2021 Revised 1 September 2021 15 September 2021 Accepted 21 September 2021 


\section{EJMBE 31,3}

\author{
Abbreviations \\ RM Risk Management \\ URRM Understanding Risk and Risk Management \\ RAA Risk Assessment and Analysis \\ RMON Risk Monitoring \\ RBV Resource-based View
}

\section{Introduction}

The preceding US financial crisis of 2007-2008 wiped out $\$ 3$ trillion from the global market and mostly affected banks [1]. Insurers were the third-largest asset managers with portfolios worth $\$ 19$ trillion; however, with few exceptions (e.g. American International Group (AIG) \& Yamato Life), insurers' prudent and conservative business policies proved to be resilient. However, the financial institutions that failed apparently applied sophisticated risk management (RM) techniques, but insurers' RM practices were stronger. If we examine the other side of the picture, excessive risk exposure and poorly executed or nearly nonexistent management of credit risk made the insurers AIG and Yamato Life insolvent (Pathak et al., 2013) [2]. Discernibly, one can argue that effective RM determines the survival of insurance companies. Therefore, we presenta model determining the antecedents of risk management practices (RMPs) in the insurance industry. Similarly, our study draws on theoretical insights from the resource-based view (RBV) and dynamic capabilities perspective (DCP) and investigates how the effectiveness of RM as a business process can yield a sustained competitive advantage for the insurance industry.

We use the RM process to assess an insurer's competitive advantage for two reasons. First, the purpose of the existence of insurance firms is to manage the risk of others. Insurance firms are perceived to be competitive in managing risks. However, insurers' business model, like other financial institutions, comprises multiple processes, such as customer services. They may have a competitive advantage in one business process and disadvantages in others. Second, the RM process, unlike others, is firm-driven whereas other processes may be market-driven. Thus, the assessment of the RM process will serve as a disaggregated measure of insurers' competitiveness.

Our model, as shown in Figure A1, shows that the RM process ${ }^{[3]}$ involves the following: (1) understanding risks and risk management (URRM), (2) risk identification (RI), (3) risk assessment and analysis (RAA), (4) RMPs and (5) risk monitoring (RMON). These components make handling those events possible and are measured by benchmarked items as recommended by various actuarial bodies, industry experts and RM laws in the USA, the UK, China and Pakistan [3]. We employ the banking sector RM model for three reasons: (1) past studies found that banks' RM practices were effective (e.g. Al-Tamimi and Al-Mazrooei, 2007; Hassan, 2009; and Hameeda and Al-Ajmi, 2012); (2) the banking sector's RM practices are fairly regulated worldwide with a more sophisticated RM regime-BASEL III - whereas insurers' RM practices are regionally controlled; and (3) to the best of our knowledge, no past study has developed an RM model for the insurance sector. However, theoretically, the link between the banking and insurance industries is inconclusive. Some researchers propose that banking and insurance services are complementary to each other (e.g. Beck and Webb, 2003). For instance, the coverage offered by insurers can hedge people from risks and thus guarantee returns for banks. Moreover, during an economic boom period, banks with improved payment systems support the rapid development of the insurance sector. In contrast, the products offered by both industries can also be substitutes (Allen and Santomero, 2001; Haiss and Sümegi, 2008), and the products offered by insurers can also capture banks' market share. This is called the "savings substitution effect". In the context of RM, we argue that stronger RM by insurers will increase their financial health, thereby promoting customer confidence. Hence, stronger RM will perform a complementary role in promoting banks' business because insurance policies are sold as bancassurance. 
Modigliani and Miller (1958) argued that in perfect markets, corporate riskiness is irrelevant to firm value. Thus, RM does not yield any competitive advantage. In contrast, some researchers have suggested that RM may bring value to firms by mitigating and/or utilizing some market imperfections. The past literature has discussed the influence of RM on firm value (e.g. Liebenberg and Hoyt (2003); Hyot and Liebenberg, 2011; Leiria et al., 2021) and performance (e.g. Meulbroek, 2002). However, it did not study RM from the perspective of the possible antecedent of a competitive advantage. In addition, past studies on RM and RBV have various shortcomings. First, the recent literature focusing on corporate risk modeling argues that the RM function in itself is endogenous (Ellul and Yerramilli, 2013; Smith and Stulz, 1985; Stulz, 2008) [4]. The endogeneity of the RM function could be due to two reasons. (1) The business process channel phenomenon when a firm's intrinsic risk culture (that is, a business process) determines both risk mitigation and the strength of the RM function. For instance, insurers having a conservative (aggressive) risk culture might be more (less) risk averse and might have a strengthened (weakened) RM function. Evidence for the business process channel was found in the work performed by Fahlenbrach and Stulz (2011). They found that financial entities that underperformed in the 1998 Russian crisis also performed poorly in the 2007-2008 financial turmoil. (2) The hedging channel phenomenon means that entities that are more prone to financial turmoil are mostly likely to be aggressive in handling risks (Froot et al., 1993; Smith and Stulz, 1985). Hence, insurers are in the business of taking risks, and they may ideally resort to taking higher risks in tandem with stronger RM.

Second, the resource-based literature (e.g. Barney, 1986, 1991; Peteraf et al., 2013; Wernerfelt, 1984; Liu et al., 2019) has used a common approach of developing measures of resources/ capabilities and theoretical criteria of yielding a sustained competitive advantage and enhancing firm performance. Furthermore, many of these studies (e.g. Farjoun, 1998; Markides and Williamson, 1994) have focused on tangible resources and used an aggregate measure of firm performance (Chen et al., 2019). Third, few empirical studies (e.g. Al-Tamimi and AlMazrooei, 2007; Hassan, 2009; Hameeda and Al-Ajmi, 2012) have investigated how RMPs are influenced by different RM processes. They showed that banks' RMPs were significantly influenced by URRM, RI, RAA and RMON. Conversely, studies covering insurers' RM practices primarily focused on risk assessment and quantification processes including risk responsibilities, capital assessment, risk reporting and decision-making and employee satisfaction (e.g. Vaughan, 2009). Past empirical studies (e.g. Acharyya and Mutenga, 2013; Atluntas et al., 2011; Tillinghast, 2006) only covered excerpts of insurers' RM framework, and they were not able to present a comprehensive RM model applicable in the dynamic market. Moreover, they also failed to address how the relationship between the RM process and its constituent components holds. This paper fills these potential research gaps and intends to perform the following: (1) address the potential issue of endogeneity by employing a latent variable RM model, (2) examine insurers' RM process within the context of the RBV and DCP, (3) investigate how insurers' RMPs are influenced by different RM-related capabilities and (4) investigate how RM can yield sustained competitive advantage for insurers.

Consequently, we contribute to the existing literature in the following ways. First, we contribute to the managerial finance literature by presenting a latent variable RM model. Past studies used three approaches to study insurers' RM: (1) using descriptive analysis to investigate the status of RM/ERM implementation (e.g. Altuntas et al., 2011; Tillinghast, 2006), (2) constructing an RM measure to study the strength of the RM function by regressing it on some micro- and macroeconomic variables (e.g. Ellul and Yerramilli, 2013) and (3) probing how a particular financial risk (e.g. credit risk) affects a given phenomenon (e.g. agency costs) (e.g. Caballero and Krishnamurthy, 2008; Leland, 1998). We argue that RM is a broad, dynamic and complex concept that cannot be measured directly (that is, it is unobservable) but rather can be inferred through other risk-related business processes. Its strength is more likely affected by a firm's internal factors than external factors. Our model
Insurers' RM as a business process 
EJMBE 31,3

\section{8}

investigates how firms' RM function (that is, RMPs) is influenced by different RM processes. Second, we contribute to the strategic management literature and investigate how insurers' RM function can yield a sustained competitive advantage under the RBV. Given the business model of the insurance industry, we assert that RM as a business process is an important source that enables insurers to realize their competitive potential. To the best of our knowledge, no study has used this approach.

The remainder of this article is structured as follows. In section 2, we discuss the theoretical background outlining the key theoretical insights of the RBV and DCP and how RM as a business process can yield a competitive advantage for the insurance sector. Section 3 discusses our model, the key variables of interest and the hypothesized relationships. Furthermore, section 4 provides details about our survey and statistical techniques employed. The empirical results and discussion are presented in section 5. Finally, section 6 concludes our article with a summary of the main findings, study limitations and future research directions.

\section{Theoretical background}

\subsection{Risk management and the RBV}

The RBV asserts that firms excel due to the resources they possess, not because of their product offerings. Ideally, firms might have access to the same pool of resources available in the market. However, one firm may be more competitive than another firm. Argumentatively, there is an intrinsic characteristic such as a "business process" that enables firms to transform these resources into valuable resources to achieve a sustained competitive advantage. The RBV argues that firms achieve and preserve competitive advantages by using worthwhile resources and capabilities that are unique (rare) (Barney, 1986, 1991; Barney and Wright, 1998; Peteraf, 2013; Wernerfelt, 1984). The theoretical expectations of theRBV suggest that not all business processes can yield a sustained competitive advantage (Ray et al., 2004). The RBV literature suggests that business processes that employ common resources can provide competitive parity. Similarly, processes using valuable and unique (rare) resources can provide a temporary competitive advantage. Furthermore, business processes employing valuable, rare and expensive to copy resources will provide a preserved competitive advantage (Barney, 1991). Accordingly, business processes applying intangible resources can be sources of sustained competitive advantages (Barney, 1991; Dierickx and Cool, 1989; Itami, 1987; Lippman and Rumelt, 1982).

A "business process is a set of routine activities that organizations take to reach their objectives" (Nelson and Winter, 1982; Porter, 1979; Ray et al., 2004). Contextually, resources are transformed into goods and services through business processes. Scholars admit that resources have the ability to give a competitive advantage depending on their utilization through business processes. Porter (1991, p. 108) argued that "resources are not valuable in and of themselves, but they are valuable because they allow firms to perform activities ... business processes are the source of competitive advantage."

$\mathrm{RM}$ as a business process represents an intangible, socially complex, causally ambiguous and path-dependent organizational resource if employed effectively and efficiently and can provide a sustainable competitive advantage to insurers. For a resource to bring a sustained competitive advantage under the RBV, it should satisfy the VRIN criteria (e.g. Barney, 1986, 1991; Peteraf, 1993; Wernerfelt, 1984; Liu et al., 2019). RM is valuable (V) because it brings value to insurers by allowing them to exploit market imperfections through risk mitigation. All insurers in the financial market conduct RM practices. However, organizational RM procedures are specific to a particular insurer only, making them rare $(R)$. Socially, the complexity characteristics of RM make it inimitable (I). Stronger (weaker) RM practices strengthen (weaken) the financial health of the insurer, and the effect is determined by their financial rating. Insurers' rating influences their market reputation. RM cannot be replaced by any other process, making it non-substitutable $(N)$. Discernibly, insurers may not be able to attribute their performance and/or market reputation to superior RM practices, which 
makes the effect causally ambiguous. RM is path-dependent and should be blended with organizational experience. The experience gained by risk managers tends to improve their competence in identifying risks, predicting their occurrence probability and effect and determining appropriate action plans.
Insurers' RM as a business process

\subsection{Risk management and dynamic capabilities perspective}

The RBV argues that firms gain a competitive advantage through their internal organization. Discernibly, the organizational strategy should focus on the market structure and the firm's strategic situation within that structure (Porter, 1979). Specifically, the RBV assumes that firms possess "bundles of resources" that are distributed unevenly among them. Furthermore, the difference in resources can also persist over time (Mahoney and Pandian, 1992; Wernerfelt, 1984; Bogodistov and Wohlgemuth, 2017). Argumentatively, the RBV has limitations in a dynamic environment. The DCP covers this limitation. Dynamic capabilities relate to "the capacity of an organization to purposefully create, extend, or modify its resource base” (Helfat and Peteraf, 2007). DCP focuses on firms' ability to adjust to expeditiously changing and immoderate environments (Teece et al., 1997).

Dynamic capabilities are traceable routines and processes that firms need to focus on to handle unforeseen circumstances and/or changing environments (dynamic market) to achieve a sustained competitive advantage. Dynamic capabilities are distinctive and pathdependent in nature, but they are notably common among firms (equivalently termed "best practice"). Eisenhardt and Martin (2000), stated that the "DCP is more homogeneous, fungible, equifinal, and substitutable than are usually assumed". The DCP serves as a mechanism by which resources are transformed into a competitive advantage (e.g. Priem and Butler, 2000). Effective RM practices represent a dynamic capability enabling insurers to handle the uncertain and rapidly changing financial market. RM is an insurer-specific and strategic organizational process that creates value. However, RM has substantial empirical research involved with it; therefore, it has significant commonalities among top insurers. That is why most common RM practices can be referred to as insurers' best practices.

\subsection{Risk management and competitive advantages}

US financial turmoil and the Eurozone sovereign credit crunch revealed that the global financial market is more sophisticated and interdependent than is usually assumed. The financial market is constantly changing to satisfy borrowers' needs. Chronologically, the financial market has shifted from conventional financing modes to more complex modes. "Wall street greed" and "incentive compensation arrangement" (Harrington and Doerpinghaus, 1993) made financial intermediaries devise structured financial instruments and hybrid securities, which significantly altered the financial market structure. For instance, credit default swaps (CDSs) converted AIG's insurance assets into mortgage-backed securities (MBSs) and collateralized debt obligations (CDOs) supported by real estate assets. Eventually, AIG lost $\$ 21$ billion and risked the solvency of the life insurance business and international financial market.

Metaphorically, the modern financial market can be classified as a high momentum market (e.g. Eisenhardt, 1989), where change has become nonlinear and capricious. Furthermore, when market borders are fogged, effective business models are hard to determine, and market drivers are ambiguous and continuously evolving. Similarly, uncertainty cannot be modeled in a high-velocity market as a probability because unforeseeable outcomes cannot be reasonably assessed (e.g. Eisenhardt and Martin, 2000). The very dynamic nature of the financial market has posed great challenges for RM in the insurance industry. To meet such challenges, insurers should convert the RM process (an intangible resource) into an organizational capability (e.g. read Cachón-Rodríguez et al., 2019, 2020, 2021). RM should give insurers the ability to assimilate, construct and reorganize 
EJMBE 31,3 internal and external expertise to consider rapid changes in the financial market. RM should be significantly less reliant on available knowledge and instead concentrate on expeditiously generating situation-specific advance knowledge. For instance, AIG sold CDSs to protect against the risk of default of corporate bonds. Usually, if this position is held until maturity without any externality, then this is an arbitrage trade. Similarly, in the long run, arbitrage trades are subject to market risk. Nonetheless, AIG's RM framework practically mapped both corporate bonds and CDS to the risk of default, ignoring systematic risk. We argue that effective RMPs can yield a competitive advantage for the insurance industry. In addition, insurers' RM process consists of different subprocesses/constructs, and the model that we present shows the hypothesized relationship between them (see section 3). Discernibly, an effective RM function should meet these relationships.

\section{The model and hypothesis development}

$\mathrm{RM}$ is a holistic process that examines whether other business processes within the firm are in agreement with its strategic objectives (Desender, 2007; Pagach and Warr, 2008; Nocco and Stulz, 2006; Regine and Bart, 2018). The financial sector also provides a mechanism to assess investment and performance decisions. Managers should develop an RM strategy consistent with the dynamic environment and the firm's risk appetite (Atluntas et al., 2011; Moreno, et al., 2021).

Efficient risk integration is the bottom line of the RM process, where interrelations among risks and risk prioritization are addressed. We argue that insurance industries such as banks and other financial institutions are exposed to similar risks, which is why we adopt the RM model previously used for the banking industry to assess the effectiveness of insurers' RMPs. Insurers have always been and will continue to be large institutional investors prone to market volatility. Furthermore, although the prior financial crisis did not affect the insurance industry much, not all insurers survived the crisis unharmed. It can be argued that large losses can still occur even if RM is flawless (Jorion, 2009). Lehman and Hoffmann (2010) stated that "the challenges emanating from the different business models and the sector-specific response of the RM practice in insurance and banking have made RM an endogenous and self-reinforcing process that over time may indeed have led to the different outcomes observed in real-time."

Nevertheless, past studies concerning insurers' RM steps (e.g. RI, RAA and RMON) slightly differ in terminologies (e.g. Carbone and Tippett, 2004; Falkner and Hiebl, 2015; Hopkins, 2015). However, they failed to find a relationship between the RM process and its components. Moreover, past empirical studies (Altuntas et al., 2011; Tillinghast, 2006) only covered excerpts of the insurers' RM framework, and they were not able to present a comprehensive RM model applicable in the dynamic environment. Insurers assume indispensable risks to achieve their strategic objectives matching their "risk appetite".

Past RM studies covering the banking sector (e.g. Al-Tamimi and Al-Mazrooei, 2007; Hassan, 2009; and Hameeda and Al-Ajmi, 2012) argue that organizational RMPs are influenced by URRM, RI, RAA and RMON. The aforementioned antecedents of the RM function are latent variables. In accordance with the previous strand of literature, we measure these latent variables through Likert scale items. Our latent variable RM model will help us determine how the relationships among these variables hold, which previous RM studies focusing on insurers were unable to capture (e.g. Atluntas et al., 2011; Tillinghast, 2006; and Yevgen and Veit, 2017). The details of these items are presented in Table A2. We will briefly discuss these latent variables here:

\subsection{RMP}

We use insurers' RMPs as the dependent variable. We measure our RMP construct with three items (i.e. RMP1, RMP2 and RMP3). Past studies have identified that for effective RM 
practices, RM procedures should be well documented (RMP1) (S\&P, 2005), and organizations should also encourage training programs in the area of RM and business ethics (RMP2) (AAA, 2013) [5].
Insurers' RM as a business process

\subsection{URRM}

$\mathrm{RM}$ is a path-dependent process. It is important not only to understand current scenarios but also to understand a series of historical events. In other words, insurers should not merely focus on "who we are" but also "how we got here" In the financial market, the majority of advancements in RM are influenced by past experiences. Risks may emerge through multiple sources, and these sources of risk emergence diminish with time, making the RM process path-dependent. We argue that for effective RM, insurers should have a clear understanding of past practices/experiences and imaginable future events at all levels within the organization. This can only be achieved through a clear understanding of commonly used RM terminologies (e.g. insurers' risk profile and risk appetite) at an individual level (Tiberius et al., 2021). URRM is the overlapping pool of individual and collective knowledge regarding how RM tools may be used to generate and sustain competitive advantages. The common understanding of RM and organizational capabilities to handle potential risks will facilitate the achievement of risk mitigation objectives by setting a common direction at all levels.

We used three (3) items to measure our URRM construct. Similarly, we ask insurance personnel whether there is a common understanding of the organizational risk profile (URRM1), risk appetite (URRM2) and risk tolerance (URRM3) at all levels. Past studies have shown that a positive link exists between URRM and banks' RMPs (e.g. Al-Tamimi and AlMazrooei, 2007; Hassan, 2009; and Hassan and Al-Ajmi, 2012). Similarly, we anticipate that URRM positively influences insurers' RMPs because a good understanding of risks and RM terminologies collectively will enhance their capacity to take the right actions.

\section{$3.3 R I$}

RM starts with the identification of various risks emerging in the dynamic environment. RI is a dynamic capability that forms the basis of the entire RM process. Effective identification of potential internal and external risks is crucial for effective and flawless risk strategy formulation. RI involves highlighting the internal (e.g. business activity) and external (e.g. industry-specific changes) factors that might affect a firm and/or risks faced and reference values (e.g. equity capital). Insurers' incompetence in RI will render the entire RM function ineffective.

The literature suggests that an organization's RI should agree with its strategic objectives (RI1), be effective (RI2) and be comprehensive (RI3). Al-Tamimi and Al-Mazrooei (2007) and Hassan (2009) reported that banks did not face any difficulty in identifying and classifying their potential risks. They also found a positive relationship between RI and RMP. We also expect that RI will positively impact insurers' RMP because the correct identification of risks will complement the entire RM process.

\subsection{RAA}

RAA involves insurers' capability of evaluating the likelihood and magnitude of the risks identified and how they align with their risk strategy and long-term goals. According to the consensus reached by policy-makers, practitioners and academia, one of the reasons for the subprime risks faced by financial institutions during the 2007-2008 crisis was the flaws in risk assessment at financial institutions. Possible explanations could be the following: (1) c-suite or highly compensated market participants knowingly took excessive tail risks and were not restrained by risk managers (Senior Supervisors Group, 2008), Kashyap et al. (2008) 
EJMBE 31,3

and (2) managers' risk assessment was hindered by historical measures, and they unknowingly ignored low-probability, nonsalient events that turned out to be significant (Botzen et al., 2010; Shleifer, 2011; Darren and Francesco, 2018; Otero et al., 2020).

We measure the RAA construct through four (4) items. Accordingly, we ask insurance personnel if their RM framework could assess risks qualitatively (RAA1) (IAA, 2008) and quantitatively (RAA2) (IAA, 2008). We also ask whether risk prioritization (RAA3) exists (EU Solvency II, 2016) and whether RAA is hindered by resource constraints (RAA4) (Al-Tamimi and Al-Mazrooei, 2007). Al-Tamimi and Al-Mazrooei (2007) and Hassan (2009) reported that banks' RMPs were positively influenced by RAA. We predict that RAA is positively linked with insurers' RMPs because insurers face resource constraints. RAA should be able to prioritize risks needing active management.

\section{$3.5 R M O N$}

RMON involves insurers' internal control capabilities including management information systems for controlling, monitoring and reporting risks. RMON aims to determine whether the risk exposures are in line with the desired level and handled properly. We asked insurance personnel whether the responsibility (RMON1) and accountability (RMON2) (IAA, 2008) for RM are understood at all organizational levels. Past studies (e.g. Al-Tamimi and Al-Mazrooei, 2007; and Hassan, 2009; To et al., 2021)) reported a positive relationship between RMON and banks' RMPs. We expect RMON to influence insurers' RMPs positively because it will assist insurers in identifying the shortcomings in the entire RM process. All of the proposed relationships among constructs are presented in appendix Figure A1.

\section{The survey}

\subsection{The instrument description}

To study the RMPs of the insurance industry, a modified version of a questionnaire previously used for banks was adopted (e.g. Al-Tamimi and Al-Mazrooei, 2007; Hassan, 2009; Hameeda and Al-Ajmi, 2012). The authors modified the questionnaire to fit the insurance sector in different regulatory regimes [6]. The questionnaire used in this study was segmented into two parts. Part 1 consisted of five nominally scaled questions related to respondent profiles such as gender, industry experience, operational position, assigned department and qualifications. It also included three questions on insurance company features: insurer type, incorporated country and majority shareholders. Part 2 included 14 ordinally scaled questions and was divided into five segments, each representing a construct to measure (i.e. URRM, RI, RAA, RMON and RMP). The ordinal questions were measured on a five-point Likert scale. The responses were measured on a continuum ranging from strongly disagree to strongly agree. The questions asked in the questionnaire were bilingual, i.e. English and Chinese.

\subsection{Data and sample description}

To achieve the study objectives, a self-administered survey was conducted covering both life and nonlife insurers operating in the USA, the UK, China and Pakistan. The questionnaire was distributed to insurance companies having a significant market share in their respective countries [7] and having AM best ratings greater than or equal to $\mathrm{B}-$. The questionnaires were randomly distributed to respondents working in the life and nonlife sectors through the social networking platform "LinkedIn". However, in China and Pakistan, where the authors had geographical access, some of the questionnaires were distributed in print versions. The survey covered the period from October 2016 to March 2017. The research was conducted on a referral basis with informal assistance from the North American Association of Insurance 
Commissioners (NAIC); the Institute and Faculty of Actuaries (UK); the Insurance Association of Pakistan (IAP); the Pakistan Society of Actuaries; Deloitte China; the University of International Business and Economics, Beijing, China and the China Association of Actuaries. Respondents who completed the questionnaire were asked to forward it to their colleagues. Respondents were provided an incentive to participate in the survey and were informed that for every successful questionnaire, one dollar would be donated to the Save the Children Inc. Syrian refugees' fund. In total 269 questionnaires were successfully filled. However, only one questionnaire from each department of an insurance company was considered, resulting in a total of 240 successfully completed questionnaires being included in this study [8]. Consequently, we were able to cover 73 insurers (i.e. 21 American, 19 British, 24 Chinese and 9 Pakistani companies) from both sectors.

The survey consisted of two phases: (1) distributing the online/print versions and collecting the completed surveys and (2) conducting a few follow-up interviews to obtain deeper insights and to find any inconsistencies among answers. According to the Swiss Re Sigma World Insurance Report 2017, the economies covered in this study contribute $44.92 \%$ of the world insurance market with respect to gross written premiums (the USA $28.9 \%$, China $28.9 \%$, the UK $7.03 \%$ and Pakistan $0.5 \%$ ). The descriptive statistics for the sample are given in Table 1.

\subsection{Statistical techniques}

The answers provided by respondents were analyzed using numerous statistical methods including descriptive statistics and multivariate data analysis. However, due to the small sample size, the statistical significance possesses small power. It is worth mentioning here that even if some tests might not produce significant results, descriptive statistics indicate statistical significance. These tests cannot be interpreted as discrepancies do not exist (see appendix Table A4). In short, considering our sample size, these differences are not adequately large to be claimed "significant" with a minute probability of error.

Because the study was survey-based, confirmatory factor analysis (CFA) and structural equation modeling (SEM) were conducted as proposed by Kline (2011). CFA provided the ability to estimate the reliability and validity of the operational model, that is, how well the data fit the measurement model. SEM analysis allowed the authors to assess the goodness-offit of the CFA solution (Cachón-Rodríguez et al., 2019, 2021). Cronbach's alpha and the average variance extracted (AVE) were calculated to assess convergent validity. Because the study was based on a multigroup survey, configural and metric invariance testing were conducted to test for measurement invariance of the questionnaire.

\section{Results and discussion}

\subsection{Convergent and discriminant validity}

We analyzed the constructs using two methods as recommended by Anderson and Gerbing (1988). First, we analyzed the five constructs represented by sixteen items using CFA. CFA is conducted to confirm the factor structures on the suggested scales. CFA was performed after removing the outliers from the dataset, as proposed by Kline (2011). Because the subsamples (i.e. the USA, the UK, China and Pakistan) were relatively small, the responses from all the countries were analyzed together. Past studies by MacCallum et al. (1999) and Jackson et al. (2001) showed that sample sizes below 100 tend to be nonconvergent.

As shown in Table 2, CFA showed that the proposed measurement model had a relatively good fit $\chi^{2}=111.384, \mathrm{DF}=62$, normed $\chi^{2}=1.797, \mathrm{RMSEA}=0.058, \mathrm{CFI}=0.974, \mathrm{IFI}=0.974$ and TLI $=0.961$ ). Thus, it can be refuted that the constructs were correctly measured by the observed variable and that their measurement power was adequate. The internal consistency assessment (Cronbach's alpha) of the constructs showed that the constituent items in the
Insurers' RM as a business process 


\section{EJMBE} 31,3

\begin{tabular}{l} 
Features \\
\hline Gender \\
Male
\end{tabular}

Frequency

162

78

67.5

Female

Experience

5 years or less

More than 5 years but less than 10 years

More than 10 years

Position

Executive/director level

Middle management level

Supervisory level

Operational level

Department

Operation

Finance

Actuary/risk management

Treasury/investment

Others

$\begin{array}{rr}30 & 12.5 \\ 65 & 27.1 \\ 29 & 12.1 \\ 116 & 48.3\end{array}$

Highest degree

Graduate

Masters

Doctorate

Professional

61

$25-10.4$

78

14

43

5.8

17.9

76

99

11

54

37.1

41.2

4.6

22.5

Type

Life

Nonlife

111

46.3

129

53.8

Incorporated country

USA

UK

28

11.7

31

12.9

China

112

46.7

Pakistan

69

28.8

Majority ownership

State-owned

71

29.6

Publicly owned

Table 1.

Foreign-owned

proposed model were reliable. The Cronbach's alpha assessment fell between the ranges of 0.711 and 0.903 , and this was far above of the minimally acceptable range of 0.6 recommended by Hair et al. (1988). The convergent validity of the measurement model was tested using the standardized factor loadings of the items. The loadings ranged from 0.679 to 0.888 at $\alpha<0.001$ and exceeded the 0.5 level. Moreover, convergent validity was also confirmed through the composite reliability assessment, and the constructs' reliability was acceptable and fell between 0.749 and 0.883 (Hair et al., 1988). The AVE of all five constructs also exceeded the minimum level of 0.5 , as proposed by Hair et al. (1988) and they fell between 0.562 and 0.722 , giving strong evidence of convergent validity (Conway and Lance, 2010; Siemsen et al., 2010). To test the discriminant validity among constructs, we needed to determine whether the correlations among constructs were significantly different from zero. The correlation confidence interval correlations $+-1.96 x$ standard error of estimate did not 


\begin{tabular}{|c|c|c|c|c|c|c|c|}
\hline Variables & $\begin{array}{l}\text { Standardized } \\
\text { loadings }\end{array}$ & $\begin{array}{c}\text { Cronbach's } \\
\text { alpha }\end{array}$ & $\begin{array}{l}\text { Construct reliability } \\
\text { (CR) }\end{array}$ & AVE & MSV & $\begin{array}{c}\operatorname{Max} R \\
(H)\end{array}$ & $\begin{array}{l}\text { Insurers RIVI } \\
\text { as a business }\end{array}$ \\
\hline URRM & & 0.829 & 0.853 & 0.659 & 0.578 & 0.854 & rocess \\
\hline URRM1 & $0.839^{* * * *}$ & & & & & & \\
\hline URRM2 & $0.791^{\text {**** }}$ & & & & & & \\
\hline URRM3 & $0.813^{* * * *}$ & & & & & & \\
\hline $\begin{array}{l}R I \\
\text { RI } 1\end{array}$ & $0859^{* * * * *}$ & 0.881 & 0.883 & 0.716 & 0.585 & 0.886 & 355 \\
\hline $\begin{array}{l}\text { RI1 } \\
\text { RI2 }\end{array}$ & $\begin{array}{l}0.859 \text { **** } \\
0.870^{\text {*** }}\end{array}$ & & & & & & \\
\hline RI3 & $0.808^{* * * *}$ & & & & & & \\
\hline$R A A$ & & 0.785 & 0.836 & 0.562 & 0.523 & 0.853 & \\
\hline RAA1 & $0.739^{* * * *}$ & & & & & & \\
\hline RAA2 & $0.715^{* * * *}$ & & & & & & \\
\hline RAA3 & $0.855^{* * * *}$ & & & & & & \\
\hline RAA4 & $0.679^{* * * *}$ & & & & & & \\
\hline$R M O N$ & & 0.837 & 0.838 & 0.722 & 0.585 & 0.849 & \\
\hline RMON1 & $0.888^{* * * *}$ & & & & & & \\
\hline RMON2 & $0.801^{* * * *}$ & & & & & & \\
\hline$R M P$ & & 0.747 & 0.749 & 0.600 & 0.521 & 0.757 & \\
\hline RMP1 & $0.813^{* * * *}$ & & & & & & \\
\hline RMP2 & $0.734^{* * *}$ & & & & & & \\
\hline \multicolumn{8}{|c|}{ 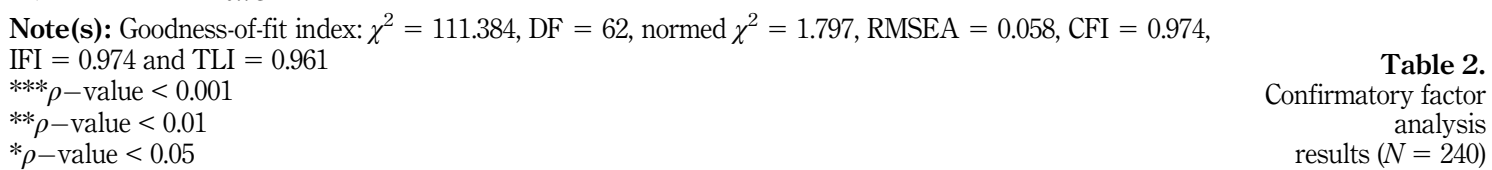 } \\
\hline
\end{tabular}

possess 1 (Joeng and Jang, 2011). We also checked the maximum shared variance (MSV) and $\max \mathrm{R}(\mathrm{H})$, which were also acceptable. Conclusively, CFA showed that the measurement model possessed both convergent and discriminant validity. For brevity, the items are indicated by abbreviations. The full forms are presented in appendix Table A2, and the correlation matrix of the constructs is presented in appendix Table A3. In the analysis available upon request, we show that none of the items were significantly correlated with each other.

Measurement invariance testing was conducted to assess how the constructs were supported by multiple groups (Kline, 2011). Due to very small country-wise subsamples, invariance testing was conducted by establishing two insurer subgroups: life and nonlife. Fan et al. (1999) studied the influence of the sample size on SEM and found that most of the model fit indices, such as the GFI, AGFI, RFI and NNFI, were affected by the sample size. Although the invariance testing results were largely influenced by a relatively small subsample size, overall, both configural invariance and metric invariance test results showed that in both groups, the constructs were represented in the same way. The invariance testing results are presented in Table 3.

\subsection{SEM model}

SEM analysis was conducted to assess the general model fit and relationships among constructs (as represented in Figure A1). The results of the SEM analysis are presented in Table 2, and the conceptual model is presented in appendix Figure A2. All of the goodness-offit indices fell between acceptable ranges, demonstrating that the structural model fit the data well. However, the significance of the chi-squared value (i.e. $\rho$-value $<0.001$ ) indicates that the estimated covariance matrix diverts significantly from the sample covariance matrix, and 


\section{EJMBE 31,3}

Table 3.

Invariance testing results

\begin{tabular}{llll}
\hline Configural invariance & Cut-off value & Metric invariance & Cut-off value \\
\hline$\chi^{2}=181.331$ & & $\chi^{2}=201.516$ & \\
DF $=124$ & & DF $=138$ & \\
$\rho-$ value $<0.001$ & & -value $<0.001$ & $1.0-3.0$ \\
Normed $\chi^{2}=1.462$ & $1.0-3.0$ & Rormed $\chi^{2}=1.460$ & $<0.08$ \\
RMSEA $=0.046$ & $<0.08$ & CFI $=0.967$ & $>0.90$ \\
CFI $=0.901$ & $>0.90$ & IFI $=0.967$ & $>0.90$ \\
IFI $=0.971$ & $>0.90$ & TLI $=0.956$ & $>0.90$
\end{tabular}

Note(s): The chi-squared difference test was conducted with the null hypothesis that the: the two groups have metric invariance to test for metric invariance. The reported $\rho$-value $=0.131$ resulting in accepting the null hypothesis

this divergence can be attributed to sampling size issues (Fan et al., 1999). To overcome this chi-squared shortcoming, the normed chi-squared was calculated, and it fell in an acceptable range of 1.0-3.0. The other indices, such as the comparative fit index (CFI), incremental fit index (IFI) and Tucker-Lewis index (TLI), significantly exceeded the cut-off value of 0.90; in contrast, the goodness-of-fit index (GFI) was relatively lower. In addition, the root mean square residual (RMR) and root mean square error of approximation (RMSEA) also fell between acceptable ranges, further confirming that the structural model fit the data well.

\subsection{Discussion}

Our findings show that comprehensive RI, improved RMON and extensive RAA by insurers will improve the effectiveness of RM function. In addition, our results also indicate that an increase in the URRM will also improve insurers' RM function, but the relationship is statistically nonsignificant (see Table 4). Our results are consistent with the findings of AlTamimi and Al-Mazrooei (2007), Hassan (2009) and Hameeda and Al-Ajmi (2012). They found that banks' RMP function was positively influenced by URRM, RI, RMON and RAA for

\begin{tabular}{lcccc}
\hline Variable relationships & Standardized estimate & $t$-statistic & $\rho$-value & Significance \\
\hline $\mathrm{RMP} \rightarrow \mathrm{RI}$ & 0.209 & 1.875 & 0.061 & $*$ \\
$\mathrm{RMP} \rightarrow \mathrm{RMON}$ & 0.345 & 2.800 & 0.005 & $* * *$ \\
$\mathrm{RMP} \rightarrow \mathrm{RAA}$ & 0.223 & 2.357 & 0.018 & $* *$ \\
$\mathrm{RMP} \rightarrow$ URRM & 0.119 & 1.188 & 0.235 & \\
\hline
\end{tabular}

Model fit indices

Cut-off value

$$
\begin{aligned}
& \chi^{2}=106.956 \\
& \text { DF }=62 \\
& \rho \text {-value }<0.001 \\
& \text { Normed } \chi^{2}=1.725 \\
& \text { RMSEA }=0.057 \\
& \text { CFI }=0.977 \\
& \text { IFI }=0.977 \\
& \text { TLI }=0.966
\end{aligned}
$$

$>0.90$

$>0.90$

Table 4.

Structure equation modeling results
Note(s): $* * * \rho-$ value $<0.01$

$* * \rho$-value $<0.05$

$* p$-value $<0.1$ 
banks operating in the Middle East region. Our results agree with RBV's expectation that intangible and socially complex resources such as URRM, RI, RMON and RAA will enhance the effectiveness of the business processes within an organization (e.g. RM). RM is a socially complex and path-dependent phenomenon; hence, insurers should have a sound understanding of the common risks and RM terminologies. This will enable insurers to purposefully create and modify their RM framework to fit the dynamic environment. URRM and RI are specialized skills (or resources) that enable management to formulate an effective organizational risk strategy consistent with their strategic goals. Furthermore, RMON and RAA are recursive business processes that enable firms to examine the effectiveness of their RM function in achieving their strategic goals. The positive relationships between RMP and URRM, RI, RAA and RMON show that insurers' RM function is effective. This supports the DCP in that effective RM can also enhance insurers' competitiveness. The goal of insurers is to bear the risk of others; and improved URRM, RI, RAA and RMON will enable them to meet their strategic goal of minimizing risks effectively. Thus, they will perform competitively.

Our results show that insurers' RMPs are positively influenced by URRM, but the relationship is nonsignificant (see Table 4). This finding is quite puzzling because studies conducted by practitioners (e.g. AAA, 2013; S\&P, 2005) recommended that there should be a common understanding of the various risks and RM terminologies at all organizational levels in the insurance industry; hence, strengthening URRM will also enhance insurers' RM framework. From practitioners' perspective, enhanced knowledge of URRM will enable insurers' personnel to better understand their perceived contribution towards organizational RM objectives. In addition, our results also show that insurers' RMPs were positively and significantly influenced by RI. Our finding related to RI is propitious for the insurance sector and is also consistent with the previous strand of literature (e.g. Al-Tamimi and Al-Mazrooei, 2007; Hassan, 2009; and Hameeda and Al-Ajmi, 2012). Comprehensive RI will correctly recognize relevant risks; hence, stronger RI will complement insurers' RM. Similarly, correct identification of the relevant risks will assist in designing appropriate RM measures. Furthermore, we also found that RAA positively and significantly influences insurers' RMPs. This promising finding is consistent with previous studies (e.g. Al-Tamimi and Al-Mazrooei, 2007; Hassan, 2009; and Hameeda and Al-Ajmi, 2012) that banks' RMPs were positively and significantly influenced by RAA. From practitioners' perspective, improving insurers' ability to assess and analyze risks will enable them to correctly match their risk-taking with their risk tolerance. Finally, our results show that insurers' RMPs are also positively and significantly influenced by RMONs. This finding is also consistent with the previous strand of literature. For instance, Hameeda and Al-Ajmi (2012) found that banks' RMPs were positively influenced by RMON. From practitioners' perspective, improved RMON will enable insurers to determine whether the risk exposures are in line with the desired level and addressed properly. It will also give insurers the ability to take corrective measures where necessary.

\section{Conclusion}

In this study, we investigated how insurers' RMPs can yield a sustained competitive advantage for the insurance industry. We did this by studying the relationship between insurers' RMPs and different RM-related capabilities/processes, namely, URRM, RI, RAA and RMON. Similarly, we found that insurers' RMPs were significantly influenced by RI, RAA and RMON. Our findings agreed with the expectations of the RBV and DCP. However, URRM did not have any influence on insurers' RMPs. We argued that insurers' RM framework, as a business process, is an intangible resource that satisfies VRIN criteria (see section 2 for the details). However, insurers' RM-related practices are significantly common in the industry and are often termed best practices. We further contend that an effective RM framework will
Insurers' RM as a business process 
EJMBE 31,3 enhance insurers' capability to purposefully create and modify their resource base to fit a high momentum financial market.

The significance of our study is supported by its unique purpose. We found that different RM-related capabilities of interest played significant roles in determining the effectiveness of insurers' RMPs. Our findings entail several practical and policy implications. These findings can generally be applied not only to the insurance industry but also to other financial institutions. For instance, from a regulatory perspective, our research findings will assist regulators in setting priority-based regulatory guidelines. Moreover, from a practitioner's perspective, our findings can be used by insurers to introduce RM-related training and development programs to rectify the shortcomings identified by this study.

The few limitations of this study are that the questions asked in this were closed-ended, respondents were required to choose among available options and they were not encouraged to provide their feedback. Second, our second limitation is the use of a 5-point Likert scale (e.g. strongly disagree to strongly agree) to measure respondents' opinions. Respondents were encouraged to select their opinion from available alternatives without providing a suitable rationale. However, the appropriate rationale could highlight the magnitude of the huge difference between the opinions.

Considering the study findings and limitations, as well as the scarce literature on insurers' RM practices, future research directions abound. The possible future directions could be secondary data analysis covering the past trends and financial shocks of the developed and emerging insurance markets to arrive at more objective findings.

\section{Endnotes}

(1) The model we have adopted has been used to assess banking sector RMPs. See AlTamimi and Al-Mazrooei (2007), Hassan (2009) and Hameeda and Al-Ajmi (2012) for further details.

(2) First, the authors incorporated the insurance literature into the questionnaire then, the questionnaire was sent to the industry experts such as CEOs, CFO's, Directors and CRO's of all the economies. They were asked to comment on the questionnaire based on their feedback the modifications were made, and the questionnaire was sent again, this process was repeated until the final draft. Afterward, a pilot study with a sample size of 100 was conducted. During the pilot study, a questionnaire was further amended based on respondents' feedback and CFA analysis. The details of the questionnaire modifications are presented in Appendix Table A1.

(3) The numerous definitions of the RM process exist in the literature. This definition is the most comprehensive one. See Bogodistov and Wohlgemuth (2017) for details.

\section{Acknowledgment}

The authors are very grateful to numerous people for assisting in the research by providing their valuable feedback on questionnaire adaptation and referring to insurance personnel. The authors would like to express their gratitude to the following people: Mr. Andrew Hitchcox, group chief risk officer, Tokio Marine Kiln Group Ltd. UK.

Mr. Colin Thores, Education Actuary, Institute and Faculty of Actuaries UK.

Mr. Nadeem Malik, Deputy Chief Executive, IGI Life Insurance, Pakistan.

Mr. Liu Hao-Yu, director, risk management department, Delloite, China.

Mr. Shan Rabbani, Head of Retail and Actuarial Services, Jubilee Life Insurance Ltd. Pakistan for helping in questionnaire adaptation. 
Mr. Tahir Ahmed, Ex-Managing Director and Chief Executive, Jubilee General Insurance Ltd. Pakistan.

Mr. Tahir Masud, Chief Executive, IGI Insurance, Pakistan.

Professor Zeng Lixin, School of Insurance and Economics, University of International Business and Economics, China.

\section{Notes}

1. International monetary fund (2009).

2. AIG suffered losses of $\$ 99.2$ billion in 2008. Furthermore, Japanese time-honored insurer Yamato Life failed with $\$ 2.7$ billion in debts.

3. We adopted the questionnaire previously used to assess the effectiveness of the risk management practices of the banking sector (e.g. Hameeda and Al-Ajmi, 2012). In addition, for each variable of interest, we incorporated recommendations made by local actuarial bodies and regulatory frameworks of the sample region (see Appendix A1 \& A2 for details). We treated these recommendations as benchmark RM practices. Moreover, we sent the final draft of the questionnaire to the key personnel (e.g. CEO, CRO, etc.) of the insurance sector of the sample region and asked for their feedback (see the Acknowledgment section for the details). Then, the questionnaire was resent to the same experts after including recommended amendments. This process was repeated until a consensus was reached.

4. An endogenous phenomenon is one that evolves within a particular system rather than outside that system.

5. For the details of the items, please refer to appendix Tables A1 and A2.

6. First, the authors incorporated the insurance literature into the questionnaire. Then, the questionnaire was sent to industry experts such as the CEOs, CFOs, directors and CROs of insurance companies operating in China, Pakistan, the UK and the USA. These experts were asked to comment on the questionnaire. Based on their feedback, modifications were made, and the questionnaire was resent again. This process was repeated until the final draft was acquired. Then, a pilot study with a sample size of 100 was conducted. During the pilot study, the questionnaire was further amended based on respondents' feedback and CFA. The details of the questionnaire modifications are presented in Appendix Table A1.

7. We calculated the market share as the sum of the direct premiums written across all product lines by a particular insurer divided by the sum of direct premiums written in fire, allied, commercial multiple perils and homeowners' lines by all insurers nationwide.

8. The reason for this is that during the survey, we noticed that similar responses were collected from the same department. However, when the responses were different, both of the filled questionnaires were considered.

\section{References}

Acharyya, M. and Mutenga, S. (2013), "The benefits of implementing enterprise risk management: evidence from the non-life insurance industry", paper presented at the 2013 Enterprise Risk Management Symposium April 22-24, 2013, Chicago.

Al-Tamimi, H.A.H. and Al-Mazrooei, F.M. (2007), "Banks' risk management: a comparison study of UAE national and foreign banks", The Journal of Risk Finance, Vol. 8 No. 4, pp. 394-409.

Allen, F. and Santomero, A.M. (2001), "What do financial intermediaries do?", Journal of Banking and Finance, Vol. 25, pp. 271-294, doi: 10.1016/S0378-4266(99)00129-6.

American Academy of Actuaries (AAA) (2013), "A public policy practice note: insurance enterprise risk management practices" (March), American Academy of Actuaries.

Anderson, J.C. and Gerbing, D.W. (1988), "Structural equation modeling in practice: a review and recommended two steps approach", Psychological Bulletin, Vol. 103 No. 3, pp. 411-423. 
EJMBE 31,3

Atluntas, M., Thomas, B.S.R. and Robert, H.E. (2011), "Implementation of enterprise risk management: evidence from the German property-liability insurance industry", The Geneva Papers on Risk and Insurance - Issues and Practice, Vol. 36 No. 03, pp. 414-439.

Barney, J.B. (1986), "Strategic factor markets: expectation, luck, and business strategy”, Management Science, Vol. 32 No. 10, pp. 1231-1241.

Barney, J. (1991), "Firm resources and sustained competitive advantage", Journal of Management, Vol. 17 No. 1, pp. 99-120.

Barney, J.B. and Wright, P.M. (1998), "On becoming a strategic partner: the role of human resource in gaining competitive advantage", Human Resource Management, Vol. 37 No. 1, pp. 31-46.

Beck, T. and Webb, I. (2003), "Economic, demographic, and institutional determinants of life insurance consumption across countries", The World Bank Economic Review, Vol. 17 No. 1, pp. 51-88.

Bogodistov, Y. and Wohlgemuth, V. (2017), "Enterprise risk management: a capability-based perspective", Journal of Risk Finance, Vol. 18 No. 3, pp. 234-251.

Botzen, W.J.W., Van den Bergh, J.C.J.M. and Bouwer, L.M. (2010), "Climate change and increased risk for the insurance sector: a global perspective and an assessment for The Netherlands", Natural Hazards, Vol. 52 No. 3, pp. 577-598.

Caballero, R.J. and Krishnamurthy, A. (2008), "Collective risk management in a flight to quality episode”, Journal of Finance, Vol. 63 No. 5, pp. 2195-2230.

Cachón-Rodríguez, G., Prado-Román, C. and Zúñiga-Vicente, J.Á. (2019), “The relationship between identification and loyalty in a public university: are there differences between (the perceptions) professors and graduates?", European Research on Management and Business Economics, Vol. 25 No. 3, pp. 122-128, doi: 10.1016/j.iedeen.2019.04.005.

Cachón-Rodríguez, G., Prado-Román, C. and Blanco-González, A. (2020), "The relationship between corporate identity and university loyalty: the moderating effect of brand identification in managing an institutional crisis", Journal of Contingencies and Crisis Management. doi: 10.1111/ 1468-5973.12342.

Cachón-Rodríguez, G., Blanco-González, A., Prado-Román, C. and Diez-Martin, F. (2021), "Sustainability actions, employee loyalty, and the awareness: the mediating effect of organization legitimacy", Managerial and Decision Economics, Vol. 42 No. 7, pp. 1730-1739, doi: $10.1002 /$ mde.3340.

Carbone, T.A. and Tippett, D.D. (2004), "Project risk management using project risk FMEA", Engineering Management Journal, Vol. 16 No. 4, pp. 28-35.

Chen, Y.L., Chuang, Y.W., Huang, H.G. and Shih, J.Y. (2019), "The value of implementing enterprise risk management: evidence from Taiwan's financial industry", North American Journal of Economics and Finance. doi: 10.1016/j.najef.2019.02.004.

Conway, J.M. and Lance, C.E. (2010), "What reviewers should expect from authors regarding common method bias in organizational research", Journal of Business and Psychology, Vol. 25 No. 3, pp. 325-334.

Darren, R.H. and Francesco, C. (2018), "Open-source intelligence for risk assessment", Business Horizons, Vol. 61 No. 5, pp. 689-697.

Desender, K. (2007), On the Determinants of Enterprise Risk Management Implementation, Working Paper, Autonomous University of Barcelona, 2007.

Dierickx, I. and Cool, K. (1989), "Asset stock accumulation and sustainability of competitive advantage”, Management Science, Vol. 35 No. 12, pp. 1504-1513.

Eisendhardt, M.K. (1989), "Building theories from case study research", Academy of Management Review, Vol. 14 No. 4, pp. 532-550.

Eisendhardt, M.K. and Martin, A.J. (2000), "Dynamic capabilities: what are they?", Strategic Management Journal, Vol. 21 Nos 10-11, pp. 1105-1121. 
Ellul, A. and Yerramilli, V. (2013), "Stronger risk controls, lower risk: evidence from U.S. Bank holding companies”, Journal of Finance, Vol. 68 No. 5, pp. 1757-1803.

Fahlenbrach, R. and Stulz, R. (2011), "Bank CEO incentives and the credit crisis", Journal of Financial Economics, Vol. 99, pp. 11-26.

Falkner, E.M. and Hiebl, M.R.W. (2015), "Risk management in SMEs: a systematic review of available evidence", The Journal of Risk Finance, Vol. 16, pp. 122-144.

Fan, X., Thompson, B. and Wang, L. (1999), "Effects of sample size, estimation methods, and model specification on structural equation modeling fit indexes", Structural Equation Modeling: A Multidisciplinary Journal, Vol. 6 No. 1, pp. 56-83.

Farjoun, M. (1998), "The independent and joint effect of the skill and physical bases of relatedness in diversification", Strategic Management Journal, Vol. 19 No. 7, pp. 611-630.

Froot, K.A., Scharfstein, D.S. and Stein, J.C. (1993), "Risk management: coordinating corporate investment and financing policies", The Journal of Finance, Vol. 48 No. 5, pp. 1629-1658.

Hair, J.F., Anderson, R.E., Thatham, R.L. and Black, W.C. (1988), Multivariate Data Analysis, 5th ed., Prentice Hall, Upper Saddle River, NJ.

Haiss, P.R. and Sümegi, K. (2008), "The relationship of insurance and economic growth - a theoretical and empirical analysis (january 3, 2007)", Emprica, Journal of Applied Economics and Economic Policy, Vol. 35 No. 4, pp. 405-431, available at: https://ssrn.com/abstract $=968243$.

Hameeda, A.H. and Al-Ajmi, J. (2012), "Risk management practices of conventional and Islamic banks in Bahrain", The Journal of Risk Finance, Vol. 13 No. 3, pp. 215-239.

Harrington, S.E. and Doerpinghaus, H.I. (1993), "The economics and politics of automobile insurance rate classification", The Journal of Risk and Insurance, Vol. 60 No. 1, pp. 59-84.

Hassan, A. (2009), "Risk management practices of Islamic banks of Brunei Darussalam", The Journal of Risk Finance, Vol. 10 No. 1, pp. 23-37.

Helfat, E.C. and Peteraf, A.M. (2007), "Understanding dynamic capabilities: progress along a developmental path", Vol. 7 No. 1, pp. 91-102.

Hopkin, P. (2015), Fundamentals of Risk Management: Understanding, Evaluating and Implementing Effective Risk Management, 3rd ed., Kogan Page, London.

Hoyt, R.E. and Liebenberg, A.F. (2011), "The value of enterprise risk management", The Journal of Risk and Insurance, Vol. 78 No. 4, pp. 795-1042.

International Actuarial Association (IAA) (2008), "Practice note on enterprise risk management for capital and solvency purposes in the insurance industry", (August), International Actuarial Association.

Itami, H. (1987), Mobilizing Invisible Assets, Harvard University Press, Cambridge, MA.

Jackson, D.L. (2001), "Sample size and number of parameter estimates in maximum likelihood confirmatory factor analysis: a monte carlo investigation", Structural Equation Modeling: A Multidisciplinary Journal, Vol. 8 No. 2, pp. 205-222.

Jeong, E.H. and Jang (Shawn), S.C. (2011), "Restaurant experiences triggering positive electronic word of mouth (eWOM) motivations", International Journal of Hospitality Management, Vol. 30 No. 2, pp. 356-366.

Jorion, P. (2009), "Risk management lessons from the credit crisis", European Financial Management, European Financial Management Association, Vol. 15 No. 5, pp. 923-933.

Kashyap, A.K., Rajan, R.G. and Jeremy, C.S. (2008), Rethinking Capital Regulation, Federal Reserve Bank of Kansas City Symposium on Maintaining Stability in a Changing Financial System, Jackson Hole, Wyoming, available at: http://www.kc.frb.org/publicat/sympos/2008/ KashyapRajanStein.08.08.08.pdf.

Kline, B.R. (2011), Principles and Practice of Structural Equation Modeling, 3rd ed., The Guilford Press, New York. 
EJMBE 31,3

\section{2}

Lehmann, A.P. and Hofmann, D.M. (2010), "Lessons learned from the financial crisis for risk management: contrasting developments in insurance and banking", The Geneva Papers on Risk and Insurance. Issues and Practice, Vol. 35 No. 1, pp. 63-78.

Leiria, M., Rebelo, E. and deMatos, N. (2021), "Measuring the effectiveness of intermediary loyalty programmes in the motor insurance industry: loyal versus non-loyal customers", European Journal of Management and Business Economics, Vols ahead-of-print Nos ahead-of-print, doi: 10.1108/EJMBE-05-2020-0103.

Leland, E.H. (1998), "Agency costs, risk management, and capital structure”, Journal of Finance, Vol. 53 No. 4, pp. 1213-1243.

Liebenberg, A.P. and Hoyt, R.E. (2003), "Determinants of enterprise risk management: evidence from the appointment of chief risk officers", Risk Management and Insurance Review, Vol. 6 No. 1, pp. 37-52.

Lippman, S. and Rumelt, R. (1982), "Uncertain imitability: an analysis of interfirm differences in efficiency under competition”, Bell Journal of Economics, Vol. 13, pp. 418-438.

Liu, H.H., Chang, A. and Shiu, Y.M. (2019), "Interest rate derivatives and risk exposure: evidence from life insurance industry", North American Journal of Finance and Economics. doi: 10.1016/j.najef. 2019.04.021.

MacCallum, R.C., Widaman, K.F., Zhang, S. and Hong, S. (1999), "Sample size in factor analysis", Psychological Methods, Vol. 4, pp. 44-99.

Mahoney, J.T. and Pandian, J.R. (1992), "The resource-based view within the conversation of strategic management”, Strategic Management Journal, Vol. 13, pp. 363-380, doi: 10.1002/smj.4250130505.

Markides, C.C. and Williamson, P.J. (1994), "Related diversification, core competencies, and corporate performance", Strategic Management Journal, Summer Special Issue, Vol. 15, pp. 149-165.

Meulbroek, L. (2002), "The promise and challenge of integrated risk management”, Risk Management and Insurance Review, American Risk and Insurance Association, Vol. 5 No. 1, pp. 55-66, September.

Modigliani, F. and Miller, M. (1958), "The cost of capital, corporation finance and the theory of investment", American Economic Review, Vol. 48 No. 3, pp. 261-297.

Moreno, I., Parrado-Martínez, P. and Trujillo-Ponce, A. (2021), "Using the Z-score to analyze the financial soundness of insurance firms", European Journal of Management and Business Economics, Vol. ahead-of-print No. ahead-of-print, doi: 10.1108/EJMBE-09-2020-0261.

Nelson, R.R. and Winter, S.G. (1982), An Evolutionary Theory of Economic Change, Harvard University Press, Cambridge, MA.

Nocco, B.W. and Stulz, R.M. (2006), "Enterprise risk management: theory and practice", Journal of Applied Corporate Finance, Vol. 18 No. 4, pp. 8-20.

Otero, L., Alaraj, R. and Lado-Sestayo, R. (2020), "How corporate governance and ownership affect banks' risk-taking in the MENA countries?", European Journal of Management and Business Economics, Vol. 29 No. 2, pp. 182-198, doi: 10.1108/EJMBE-01-2019-0010.

Pagach, D. and Warr, R. (2008), The Effects of Enterprise Risk Management on Firm Performance, Working Paper, North Carolina State University.

Pathak, V., Jena, B. and Kalra, S. (2013), “Qualitative research”, Perspectives in Clinical Research, Vol. 4, p. 192.

Peteraf, M. (1993), "The cornerstones of competitive advantage: a resource-based view", Strategic Management Journal, Vol. 14, pp. 179-191, doi: 10.1002/smj.4250140303.

Peteraf, M., Di Stefano, G. and Verona, G. (2013), "The elephant in the room of dynamic capabilities: bringing two diverging conversations together", Strategic Management Journal, Vol. 34 No. 12, pp. 1389-1410. 
Porter, M.E. (1991), “Towards a dynamic theory of strategy”, Strategic Management Journal, Vol. 12 No. 1 , pp. 95-117.

Porter, M.E. (1979), "How competitive forces shape strategy", Harvard Business Review, Vol. 57, pp. 137-145.

Priem, R.L. and Butler, E.J. (2000), "Is the resource-based 'view' a useful perspective for strategic management research?”, The Academy of Management Review, Vol. 26 No. 1, pp. 22-40.

Ray, G., Barney, J.B. and Muhanna, A.W. (2004), "Capabilities, business processes, and competitive advantage: choosing the dependent variable in empirical tests of the resource-based view", Strategic Management Journal, Vol. 25, pp. 23-37.

Regine, S. and Bart, D. (2018), "Transforming under deep uncertainty: a strategic perspective on risk management”, Business Horizons, Vol. 61 No. 5, pp. 733-743.

Senior Supervisors Group (2008), "Observation of risk management practices during the recent market turbulence".

Shleifer, A. (2011), The transformation of finance, Lecture at American Finance Association Meetings, available at: http://scholar.harvard.edu/files/shleifer/files/transformation of finance afa jan2011.pdf.

Siemsen, E., Roth, A. and Oliveira, P. (2010), "Common method bias in regression models with linear, quadratic, and interaction effects", Organizational Research Methods, Vol. 13 No. 3, pp. 456-476.

Smith, C.W. and Stulz, R. (1985), "The determinants of firms' hedging policies”, Journal of Financial and Quantitative Analysis, Vol. 28, pp. 391-405.

Standard and Poor's (S\&P) (2005), "Evaluating the enterprise risk management practices of insurance companies", (October), Standard and Poor's, pp. 1-47.

Stulz, R. (2008), "Risk management failures: what are they and when do they happen?", Journal of Applied Corporate Finance, Vol. 20, pp. 58-67.

Teece, J.D., Pisano, G. and Shuen, A. (1997), "Dynamic capabilities and strategic management", Strategic Management Journal, Vol. 18 No. 7, pp. 509-533.

Tiberius, V., Schwarzer, H. and Roig-Dobón, S. (2021), "Radical innovations: between established knowledge and future research opportunities", Journal of Innovation and Knowledge, Vol. 6 No. 3, pp. 145-153, doi: 10.1016/j.jik.2020.09.001.

Tillinghast (2006), "Risk management", Risk Opportunity, The 2006 Tillinghast ERM Survey, Tillinghast.

To, T.A., Suzuki, Y., Ho, H.T.T., Tran, S.T. and Tran, T.Q. (2021), "The risk management role of nonexecutive directors: from capital expenditure perspective", European Journal of Management and Business Economics, Vol. 30 No. 2, pp. 152-169, doi: 10.1108/EJMBE-122019-0237.

Vaughan, M.T. (2009), "The economic crisis and lessons from (and for) US regulation”, Journal of Insurance Regulation, Vol. 2015, pp. 1-18.

Wernerfelt, B. (1984), “A resource-based view of the firm”, Strategic Management Journal, Vol. 5 No. 2 , pp. 171-180.

Yevgen, B. and Veit, W. (2017), "Enterprise risk management: a capability-based perspective", The Journal of Risk Finance, Vol. 18 No. 3, pp. 234-325.

\section{Further reading}

LE (1992), "Competing on capabilities: the new rules of corporate strategy", Harvard Business Review, Vol. 70 No. 2, pp. 57-69. 


\begin{tabular}{llll}
\hline Item & Source & Item & Source \\
\hline URRM1 & AAA (2013) & RAA2 & IAA (2008) \\
URRM2 & S\&P (2005) & RAA3 & AAA, 2013; EU solvency II \\
URRM3 & S\&P (2005) & RAA4 & Hameeda and Al-Ajmi (2012) \\
RI1 & Hameeda and Al-Ajmi (2012) & RMON1 & S\&P (2005) \\
RI2 & S\&P, 2005, AAA, 2013 & RMON2 & S\&P (2005) \\
RI3 & EU solvency II Directive & RMP1 & S\&P (2005) \\
RAA1 & IAA (2008) & RMP2 & AAA (2013) \\
\hline
\end{tabular}

Table A1.

Item modification references (5-point Likert scale: 1-strongly disagree to 5 strongly agree)

\section{Appendix}

AAA (2013)

Hameeda and Al-Ajmi (2012)

EU solvency II Directive

IAA (2008)

Item Description

URRM1 There is a common understanding of our organizational risk profile at all levels

URRM2 There is a common understanding of our organizational risk appetite at all levels

URRM3 There is a common understanding of our organizational risk tolerance at all levels

RI1 Our risk management strategy is in agreement with our organizational objectives

RI2 We have an effective risk identification in place

RI3 Our risk identification procedure is comprehensive

RAA1 Potential shocks (risks) to our business are assessed by using quantitative analysis methods

RAA2 Potential shocks (risks) to our business are assessed by using qualitative analysis methods (e.g. high, moderate and low)

RAA3 Our response to analyzing risk includes prioritizing risk and selecting those that need active management

RAA4 Our response to analyzing risks are hindered by resource constraints

RMON1 Responsibility for risk management is clearly set out and understood at all levels

RMON2 Accountability for risk management is clearly set out and understood at all levels

RMP1 Our risk management procedures and processes are documented and provide guidance to staff about managing risks

Table A2. RMP2 Our organizational policy encourages training programs in the area of risk management as well as, Items description business ethics

\begin{tabular}{llllll}
\hline Constructs & URRM & RI & RAA & RMON & RMP \\
\hline URRM & 1 & & & & \\
RI & 0.683 & 1 & & & \\
RAA & 0.572 & 0.723 & 1 & 1 & 1 \\
RMON & 0.760 & 0.765 & 0.661 & 0.722 & \\
RMP & 0.622 & 0.710 & 0.677 & & \\
Note(s): all the correlations were significant at 0.01 level & & &
\end{tabular}




\section{EJMBE \\ 31,3}

\section{6}

Figure A1.

Proposed RM model relationships

Figure A2.

Standardized regression estimates for SEM analysis
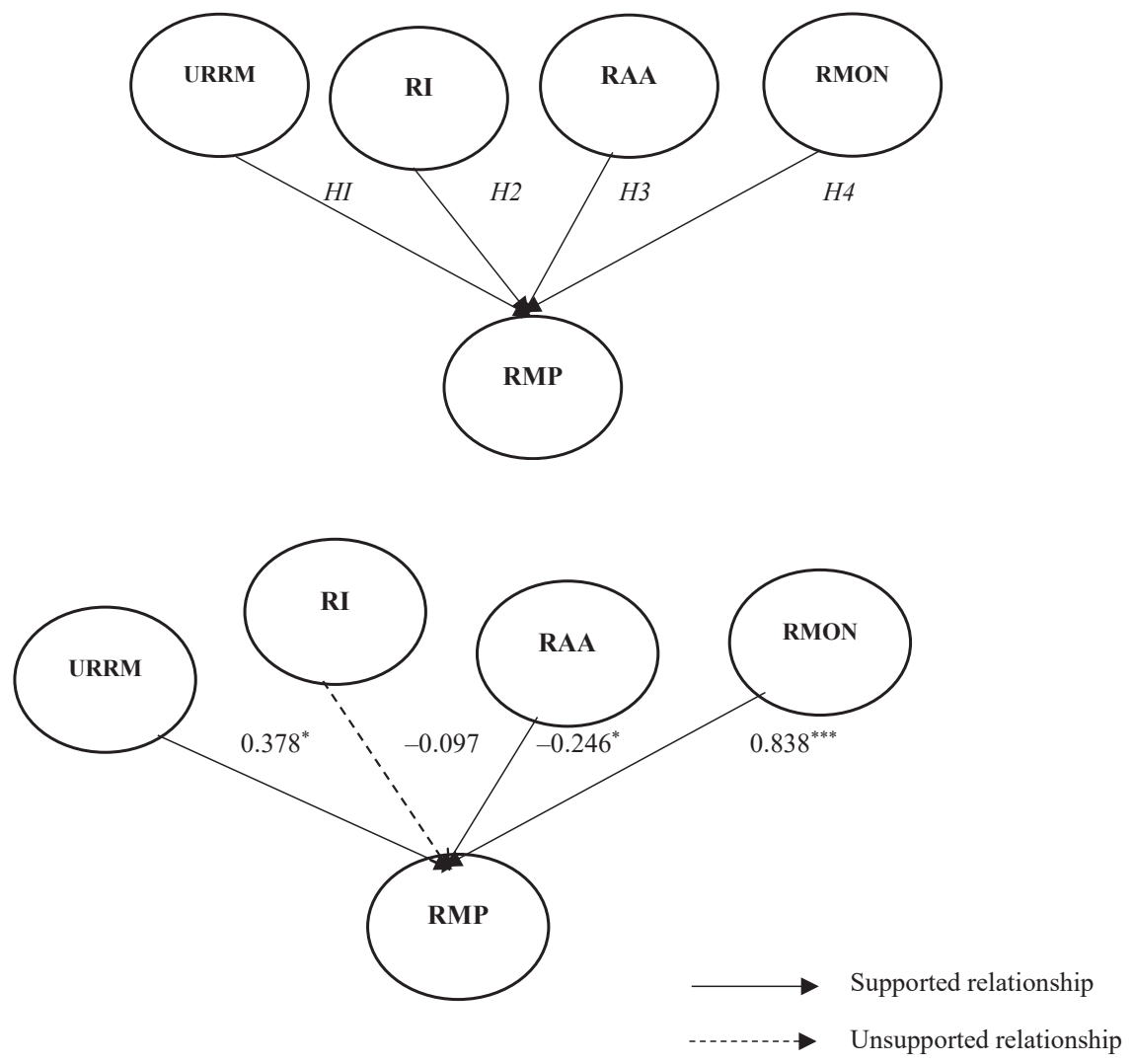

Note(s): ${ }^{* * *} \rho$ - value $<0.1 ; * * \rho-$ value $<0.05 ;{ }^{*} \rho$ - value $<0.001$;

\section{Corresponding author}

Danish Ahmed can be contacted at: danish.ahmed88@live.com

For instructions on how to order reprints of this article, please visit our website:

www.emeraldgrouppublishing.com/licensing/reprints.htm

Or contact us for further details: permissions@emeraldinsight.com 